\title{
ARBORIZAÇÃO DE VIAS PÚBLICAS EM NOVA IGUAÇU, RJ: O CASO DOS BAIRROS RANCHO NOVO E CENTRO ${ }^{1}$
}

\begin{abstract}
Rodrigo Tavares da Rocha², Paulo Sérgio dos Santos Leles ${ }^{3}$, Sílvio Nolasco de Oliveira Neto ${ }^{3}$
RESUMO - Os objetivos deste trabalho foram quantificar e qualificar a arborização de ruas dos Bairros Rancho Novo e Centro, na cidade de Nova Iguaçu, RJ. Através de inventário total, foram encontrados 560 indivíduos pertencentes a 46 espécies no Bairro Rancho Novo e, no Bairro Centro, 1.374 e 59, respectivamente. Em ambos os bairros, cerca de $91 \%$ das plantas pertenciam às 20 espécies mais freqüentes, sendo Ficus benjamina e Cássia siamea as predominantes em Rancho Novo (21,6\%) e Centro (19,1\%), respectivamente. O Bairro Rancho Novo apresentou $18 \%$ de suas vias públicas arborizadas e o Bairro Centro, 13,5\%. Cerca de $95 \%$ das espécies foram enquadradas como de pequeno e médio portes. As maiores médias de altura foram observadas em plantas de Cássia siamea, em Rancho Novo e amendoeira no Centro. As espécies plantadas sob rede aérea representaram $40 \%$ da população arbórea, sendo $45 \%$ desta com conflitos evidentes. No Bairro Centro, $62 \%$ das árvores necessitavam de poda, enquanto em Rancho Novo a poda é recomendada em $50 \%$ das plantas. Elevada discrepância foi constatada nas distâncias médias entre árvores, com valores médios de 56 m no Bairro Rancho Novo e 74 m no Bairro Centro. Recomenda-se a substituição gradativa de Cássia siamea, amendoeira, "flamboyant" e sombreiro por outras espécies mais adequadas à arborização urbana.
\end{abstract}

Palavras-chave: arborização urbana, arboricultura, inventário e Nova Iguaçu.

\section{TREE PLANTING ON PUBLIC ROADS IN NOVA IGUAÇU, RJ: THE CASE OF NOVO RANCHO AND DOWNTOWN DISTRICTS}

\begin{abstract}
The objectives of this work were to quantify and qualify the urban trees of Rancho Novo District and Downtown Area of Nova Iguaçu City, State of Rio de Janeiro, Brazil. Through the total inventory, 560 individuals distributed in 46 species were found in Rancho Novo District, in contrast to 1,374 individuals and 59 species in Downtown Area. In both areas, about $91 \%$ of the plants are among the 20 most frequent species, with Ficus benjamina and Cassia siamea predominating in Rancho Novo $(21,6 \%)$ and Downtown $(19,1 \%)$, respectively. Rancho Novo District presented $18 \%$ of arboured public areas against 13,5\% of Downtown Area. About 95\% of the species were considered as small and medium sizes. The largest height averages were reached by Cassia siamea, in Rancho Novo, and almond trees in Downtown. The species located under electric lines represented $40 \%$ of the tree population, being $45 \%$ of those trees with evident conflicts. In the Downtown Area, $62 \%$ of the population needs pruning, with cleaning being the most important requirement, while in Rancho Novo District pruning is recommended for $50 \%$ of the population, mainly Ficus benjamina $(14,5 \%)$. Cassia siamea is the most pruning demanding species in Downtown, with 25,8\% of the recommendations. Large discrepancies were found for tree spacing, with average values of $56 \mathrm{~m}$ in Rancho Novo District and $74 \mathrm{~m}$ in Downtown Area. The substitution of Cassia siamea, amendoeira, flamboyant and sombreiro by more appropriate species of urban trees is recommended.
\end{abstract}

Key words: Urban trees, street arborization, inventory and Nova Iguaçu.

\footnotetext{
${ }^{1}$ Recebido para publicação em 14.3.2003 e aceito para publicação em 10.8.2004.

${ }^{2}$ Prefeitura Municipal de Paracambi-RJ. E-mail: <rodrigo.rtr@bol.com.br>.

${ }^{3}$ Universidade Federal Rural do Rio de Janeiro. E-mail: <pleles@ufrrj.br e/snolasco@ufrrj.br>.
} 


\section{INTRODUÇÃO}

Atualmente, o Brasil apresenta $80 \%$ de sua população vivendo nas grandes cidades (IBGE, 2000). Em muitas dessas cidades, a elevada concentração populacional e as atividades industriais ocasionam sérios problemas ambientais, como: impermeabilização do solo e poluições atmosférica, hídrica, sonora e visual, além da redução da cobertura vegetal.

O conhecimento e a análise das estruturas das cidades e suas funções, através das óticas econômica, social e ambiental, são pré-requisitos básicos para o planejamento e administração das áreas urbanas, na busca de melhores condições de vida para os seus habitantes. Nesse contexto, e pelos seus próprios objetivos, a arborização urbana assume importância particular.

A vegetação presente nas cidades tem numerosos usos e funções no ambiente urbano. Pode-se perceber nas cidades as diferenças entre as regiões arborizadas e aquelas desprovidas de arborização (SILVA, 1998). Os locais arborizados geralmente se apresentam mais agradáveis aos sentidos humanos. Segundo Sanchotene (1994) e Vidal e Gonçalves (1999), a presença de arbustos e árvores no ambiente urbano tende a melhorar o microclima através da diminuição da amplitude térmica, principalmente por meio da evapotranspiração, da interferência na velocidade e direção dos ventos, sombreamento, embelezamento das cidades, diminuição das poluições atmosférica, sonora e visual e contribuição para a melhoria física e mental do ser humano na cidade.

Para se conhecer a arborização urbana, é necessária a sua avaliação, que depende da realização de inventário. O inventário da arborização tem como objetivo geral conhecer o patrimônio arbustivo e arbóreo de uma localidade. Tal levantamento é fundamental para o planejamento e manejo da arborização, fornecendo informações sobre a necessidade de poda, tratamentos fitossanitários ou remoção e plantios, bem como para definir prioridades de intervenções. O tipo de inventário utilizado deverá ser em função dos objetivos especificamente definidos, fundamentados em diferentes metodologias e graus de precisão (TAKAHASHI, 1994; MOTTA, 1998; COSTA e HI-
GUCHI, 1999; MILANO e DALCIN, 2000). Segundo Milano (1994), os inventários podem ser por amostragem ou inventário total. Este último é mais direcionado para locais onde a freqüência da arborização é muito heterogênea entre vias públicas ou bairros, ou em cidades de pequeno porte, conforme utilizado por Robayo (1993), Teixeira et al. (1994), Costa et al. (1996) e Silva (2000). Em cidades de maior porte, o inventário total é inviável devido ao tempo e recursos necessários para a sua realização (TAKAHASHI, 1994). Nos inventários por amostragem podem ser adotados sistemas aleatórios, sistemáticos ou conglomerados. Segundo Milano (1994), são as características da cidade e os objetivos da avaliação e, por conseqüência, dos dados a coletar, que definirão o sistema a ser adotado. Os levantamentos da arborização urbana no Brasil vêm crescendo, sendo pioneiros os realizados em Curitiba (MILANO, 1984), Recife (BIONDI, 1985) e Maringá (MILANO, 1988).

Durante décadas, a arborização de Nova Iguaçu foi praticamente esquecida pelo poder público, sendo grande parte das árvores existentes decorrente de plantios voluntários sem planejamento e acompanhamento técnico. Problemas desse tipo são provenientes da falta de planejamento urbano como um todo e, especificamente, no que se refere à arborização urbana. Além disso, os gastos da Prefeitura Municipal com poda são considerados elevados, chegando a aproximadamente $90 \%$ dos recursos gastos na arborização urbana (Almeida, L.M ${ }^{1}$. - Comunicação pessoal), por não apresentar caráter preventivo e sim emergencial, devido à ausência de planejamento.

Este trabalho objetivou caracterizar, de maneira quantitativa e qualitativa, a arborização das vias públicas dos Bairros Rancho Novo e Centro, na cidade de Nova Iguaçu, Estado do Rio de Janeiro, e fornecer subsídios para o planejamento e aplicação de medidas mitigadoras.

\section{MATERIAL E MÉTODOS}

\subsection{Caracterização da área}

A cidade de Nova Iguaçu está entre as oito mais populosas do Estado do Rio de Janeiro, com 915.336 habitantes (IBGE, 2000). Possui área de 559,4 km² (71 bair-

${ }^{1}$ Luney Martins de Almeida - Supervisão de Praças e Jardins da Prefeitura Municipal de Nova Iguaçu.

R. Árvore, Viçosa-MG, v.28, n.4, p.599-607, 2004 
ros), localizada na altitude de $25 \mathrm{~m}$, com predomínio de clima quente com temperatura média anual de $25^{\circ} \mathrm{C}$ e precipitação média anual de $1.595 \mathrm{~mm}$. Atualmente, o setor econômico mais representativo em Nova Iguaçu é o terciário, sendo o mais importante centro comercial e de serviços da região, para onde convergem, também, moradores de municípios vizinhos (PROTETORES DA VIDA, 2002ab).

O Bairro Rancho Novo caracterizou-se como residencial e comercial, com uma indústria têxtil localizada às margens da rodovia Presidente Dutra. $\mathrm{O}$ Bairro Centro foi caracterizado pela elevada quantidade de estabelecimentos de comércio varejista, com maior destaque para os de gêneros alimentícios. Apresentou perfil estratificado, sendo comercial e industrial na sua maior parte e residencial na área ao sul, caracterizando a área nobre do município. Ambos os bairros não possuem cadastro ou histórico de sua arborização.

\subsection{Coleta de dados}

Em ambos os bairros, o método de inventário utilizado no levantamento foi de caráter quali-quantitativo, do tipo censo, também denominado inventário total.

Os dados foram coletados no período de agosto a outubro de 1999, em formulário específico, com as seguintes informações: data da coleta, nome e extensão do logradouro, nome do bairro, nome da espécie, presença de rede aérea, altura da planta, CAP (circunferência à altura do peito), diâmetro da copa (sentido longitudinal e transversal ao meio fio, sendo aqueles de valor zero relacionados com podas danosas - em sua maioria - e tratamentos fitossanitários emergenciais) e recomendações de poda.

Para localização das vias públicas, bem como a obtenção de suas extensões, foi utilizada numa planta planialtimétrica na escala 1:10.000, elaborada pela Fundação Centro de Informações e Dados do Rio de Janeiro (CIDE), com informações da malha viária dos Bairros Centro e Rancho Novo.

As plantas que estavam em conflitos, ou mesmo em potencial conflitos com a rede aérea, foram distribuídas em três classes de altura, considerando-se as seguintes informações: rede telefônica $=6,0 \mathrm{~m}$; rede de baixa tensão $=7,2 \mathrm{~m}$; e rede de alta tensão $=8,8 \mathrm{~m}$.
As podas foram recomendadas de acordo com a presença de conflitos e necessidade de manejo (adaptado de CEMIG, 1994). São elas: poda de conformação é aquela realizada respeitando-se as formas da planta adulta. Essa poda é adotada para controlar o crescimento e, ou, adequar a forma da árvore ao espaço onde está plantada; poda de formação - eliminação de ramos com crescimento irregular nas fases de muda e jovem, visando à formação correta da planta quando adulta; poda de limpeza - eliminação de galhos mortos, doentes, parasitas e ramos epicórmicos; poda de rebaixamento - quando o indivíduo apresenta conflitos com estruturas de serviço ou construções; e remoção - necessidade de corte do indivíduo devido à incompatibilidade entre seu porte e o espaço disponível, ou quando seu estado for irrecuperável, devido a danos físicos ou problemas fitossanitários.

A freqüência relativa de cada espécie foi calculada através da razão entre o número de indivíduos da espécie e o número total de indivíduos do bairro, multiplicada por 100 .

\section{RESULTADOS E DISCUSSÃO}

\subsection{Espécies e freqüência relativa}

Nas ruas e avenidas do Bairro Rancho Novo, foram encontradas 560 plantas arbustivas e arbóreas, pertencentes a 46 espécies, sendo 20 delas responsáveis por $91 \%$ das plantas levantadas (Tabela 1). Em 19 indivíduos não foi possível identificar a espécie.

De acordo com as recomendações de Grey e Deneke (1978), citados por Milano e Dalcin (2000), cada espécie não deve ultrapassar 10-15\% do total de indivíduos da população arbórea, para um bom planejamento da arborização urbana. Dentro desse aspecto, no Bairro Rancho Novo, ficus benjamina foi a espécie que predominou (com 21,6\% do total), fugindo às recomendações desses autores. Além disso, a predominância de apenas uma espécie ou grupo de espécies pode facilitar a propagação das pragas, atualmente muito comum nas árvores em ambiente urbano. Fícus benjamina mostrou-se prejudicial à estrutura viária da cidade, sendo observados danos ao calçamento e conflitos com as redes aéreas, embora tais observações não tenham sido detalhadas neste estudo. Santana e Santos (1999) comentaram que o gênero Ficus é causador de problemas como elemento de arborização no Campus da Universidade Estadual de Feira de Santana (UEFS), por danificar calçadas.

R. Árvore, Viçosa-MG, v.28, n.4, p.599-607, 2004 
Tabela 1 - Vinte espécies de maior freqüência relativa nas vias públicas do Bairro Rancho Novo, na cidade de Nova Iguaçu, RJ

Table 1-The twenty most frequent species found in the public areas of Rancho Novo district, in Nova Iguaçu, Rio de Janeiro State

\begin{tabular}{|c|c|c|c|}
\hline Nome comum & Nome científico & N. ${ }^{\circ}$ ind. & $\mathrm{f}(\%)$ \\
\hline Ficus benjamina & Ficus benjamina L. & 121 & 21,61 \\
\hline Amendoeira & Terminalia catappa $\mathrm{L}$. & 56 & 10,00 \\
\hline Oiti & Licania tomentosa (Benth.) Fritsch. & 49 & 8,75 \\
\hline Cássia siamea & Cassia siamea Lam. & 35 & 6,25 \\
\hline Extremosa & Lagerstroemia indica $\mathrm{L}$. & 28 & 5,00 \\
\hline Albizia & Albizia lebbeck (L.) Benth. & 23 & 4,11 \\
\hline Ipê-amarelo & Tabebuia chrysotricha (Mart. ex DC.) Standl. & 23 & 4,11 \\
\hline Sombreiro & Clitoria fairchildiana R.A. Howard & 22 & 3,93 \\
\hline Flamboyant & Delonix regia (Bojer ex Hook.) Raf. & 21 & 3,75 \\
\hline Munguba & Pachira aquatica Äubl. & 20 & 3,57 \\
\hline Pata-de-vaca & Bauhinia variegata L. & 18 & 3,21 \\
\hline Jasmim-manga & Plumeria rubra $\mathrm{L}$. & 16 & 2,86 \\
\hline Aroeira & Schinus terebinthifolia Raddi & 13 & 2,32 \\
\hline Cássia-imperial & Cassia fistula $\mathrm{L}$. & 11 & 1,96 \\
\hline Goiabeira & Psidium guajava L. & 8 & 1,43 \\
\hline Murta & Murraya exotica $\mathrm{L}$. & 7 & 1,25 \\
\hline Tuia & Cupressus macrocarpa Hartw. & 7 & 1,25 \\
\hline Algodoeiro-da-praia & Hibiscus pernambucensis Arruda & 6 & 1,07 \\
\hline Areca & Dypsis lutescens H. Wendl. & 6 & 1,07 \\
\hline Não identificada & & 19 & 3,39 \\
\hline
\end{tabular}

No Bairro Centro foram encontrados 1.374 indivíduos arbustivos e arbóreos, pertencentes a 59 espécies, sendo 54 desses indivíduos não identificados. As 20 espécies mais freqüentes englobam 91,9\% das plantas presentes no bairro (Tabela 2), sendo as três de maior ocorrência a cássia siamea (19,1\%), a amendoeira (10,5\%) e o ficus benjamina (10,3\%). Essas espécies também estão entre as de maior ocorrência no Bairro Rancho Novo, conforme mostrado na Tabela 1. Observou-se que, constantemente, a espécie cássia siamea apresentava rachaduras, desprendimento de galhos e, em alguns casos, a queda da árvore, causando riscos à população e aos bens públicos e particulares.

Tabela 2 - Vinte espécies arbustivas e arbóreas de maior freqüência relativa nas vias públicas do Bairro Centro, na cidade de Nova Iguaçu, RJ

Table 2 - The twenty most frequent species found in the public areas of Downtown, in Nova Iguaçu, Rio de Janeiro State

\begin{tabular}{|c|c|c|c|}
\hline Nome Vulgar & Nome científico & N. ${ }^{\circ}$ ind. & $f(\%)$ \\
\hline Cássia siamea & Cassia siamea Lam. & 263 & 19,14 \\
\hline Amendoeira & Terminalia catappa L. & 144 & 10,48 \\
\hline Ficus benjamina & Ficus benjamina $\mathrm{L}$. & 141 & 10,26 \\
\hline Flamboyant & Delonix regia (Bojer ex Hook.) Raf. & 125 & 9,10 \\
\hline Oiti & Licania tomentosa (Benth.) Fritsch. & 119 & 8,66 \\
\hline Aroeira & Schinus terebinthifolia Raddi & 62 & 4,51 \\
\hline Sombreiro & Clitoria fairchildiana R.A. Howard & 47 & 3,42 \\
\hline Munguba & Pachira aquatica Aubl. & 46 & 3,35 \\
\hline Extremosa & Lagerstroemia indica $\mathrm{L}$. & 45 & 3,28 \\
\hline Pata-de-vaca & Bauhinia variegata $\mathrm{L}$. & 42 & 3,06 \\
\hline Albizia & Albizia lebbeck (L.) Benth. & 32 & 2,33 \\
\hline Ipê-amarelo & Tabebuia chrysotricha (Mart.) Standl. & 26 & 1,89 \\
\hline Algodão-da-praia & Hibiscus pernambucensis Arruda & 23 & 1,67 \\
\hline Espatódea & Spathodea campanulata Beauv. & 21 & 1,53 \\
\hline Cássia-imperial & Cassia fistula L. & 18 & 1,31 \\
\hline Hibisco & Hibiscus rosa-sinensis L. & 16 & 1,16 \\
\hline Ipê-de-jardim & Tecoma stans (L.) juss. ex H.B.K. & 13 & 0,95 \\
\hline Mangueira & Mangifera indica $\mathrm{L}$. & 13 & 0,95 \\
\hline Goiabeira & Psidium guajava L. & 12 & 0,87 \\
\hline Não identificada & & 54 & 3,93 \\
\hline
\end{tabular}

R. Árvore, Viçosa-MG, v.28, n.4, p.599-607, 2004 
A grande diversidade de espécies, segundo Costa et al. (1996), não parece contribuir para trazer identidade, definição espacial ou coerência visual ao bairro. Provavelmente esse grande número de espécies - 46 em Rancho Novo e 59 no Centro - seja proveniente de plantios contínuos e aleatórios, realizados pela própria população local. Devido a isso, ocorreram 19 espécies com apenas um indivíduo, correspondendo a 3\% do total dos indivíduos no Bairro Rancho Novo. No Centro, foram encontradas 15 espécies com apenas um indivíduo, correspondendo a $1,1 \%$ da população arbórea do bairro.

Outra indicação importante do grau de interferência da população local na arborização são a presença e a variedade de árvores frutíferas plantadas nas calçadas, compondo aproximadamente $5 \%$ da arborização do Bairro Rancho Novo e 4\% do Centro. Goiabeiras, mangueiras, jaqueiras e jambeiros estão distribuídos de maneira aleatória pelas calçadas, revelando, talvez, um desejo oculto de um verdadeiro pomar urbano. Constatou-se que a maioria desses indivíduos estava bastante comprometida devido à poluição e depredação.

Entre as 10 espécies de maior ocorrência nos dois bairros estudados (Tabelas 1 e 2), amendoeira, cássia siamea, flamboyant e sombreiro não estão sendo indicadas para arborização de ruas da cidade do Rio de Janeiro (Vasconcelos ${ }^{2}$, H. - Comunicação pessoal). A primeira espécie possui folhas grandes, que nos meses de julho e agosto se desprendem das árvores, sujando as calçadas e ruas, além de causar entupimento da rede pluvial (bocas-de-lobo). Cássia siamea é uma espécie de rápido crescimento, cuja madeira é de baixa densidade e, conseqüentemente, baixa resistência mecânica, quebrando com facilidade, o que pode causar transtornos devido à queda de galhos. Flamboyant não é indicado para arborização de ruas, por apresentar raízes superficiais que podem danificar as calçadas. Além disso, Coutinho et al. (1998) constataram a presença significativa do Cerambicídeo Oncideres saga, conhecido como serrador, em árvores de flamboyant da arborização do Campus da UFRRJ, em Seropédica, município vizinho ao de Nova Iguaçu. O sombreiro é uma espécie que apresenta ataque de insetos desfolhadores em toda a região metropolitana do Rio de
Janeiro. Monteiro e Campos (1994) constataram ataque de Urbanus acawoiose Guajará (2001) deEuphalerus clitorae, causando severos danos a árvores dessa espécie no ambiente urbano. Tais insetos se alimentam dos folíolos dos sombreiros, deixando as árvores totalmente desfolhadas.

Outra espécie que está entre as 10 mais freqüentes neste estudo, e que também é bastante atacada por praga, é a albizia. Coutinho et al. (1998) constataram ataques significativos de Oncideres saga em árvores de albizia no Campus da UFRRJ, ocasionando queda de galhos.

\subsection{Classes de altura}

A distribuição de altura dos indivíduos em classes, nos dois bairros estudados, é mostrada na Figura 1 . No Bairro Centro, $28,6 \%$ dos indivíduos apresentaram altura igual ou inferior a $3,5 \mathrm{~m}$, evidenciando que as plantas são muito jovens ou têm problemas de implantação, como plantio de mudas de má qualidade e, ou, escolha de espécies de difícil adaptação às condições locais. Durante o levantamento foi observado que as plantas estavam sendo mal conduzidas; outra hipótese a ser considerada é a redução do seu porte, em razão da prática de poda.

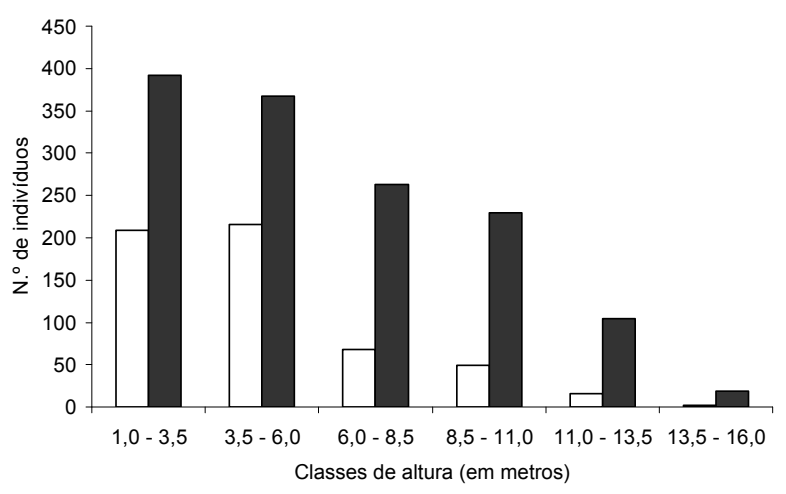

Figura 1 - Número de indivíduos, em diferentes classes de altura, da arborização de vias públicas dos Bairros Rancho Novo $(\square)$ e Centro $(\square)$, na cidade de Nova Iguaçu, RJ.

Figure 1 - Number of individuals, of different height classes, of urban trees in Rancho Novo ( $\square$ ) and Downtown (ם), Nova Iguaçu, Rio de Janeiro State

${ }^{2}$ Hermano Vasconcelos, Eng. Florestal da Fundação Parques e Jardins - Prefeitura da Cidade do Rio de Janeiro. 
Aproximadamente 55\% das plantas do Bairro Centro apresentavam altura inferior a $6 \mathrm{~m}$, às quais, teoricamente, sofreriam apenas conflitos com os cabos aéreos de telefone. Acima de $6 \mathrm{~m}$ e inferior a $11 \mathrm{~m}$ de altura encontravam-se $35,8 \%$ das árvores, conflitando com a rede de baixa tensão.

Com altura superior a $11 \mathrm{~m}$ encontravam-se $9 \%$ das árvores do Bairro Centro, que, potencialmente, poderiam conflitar com a rede de alta tensão. No Bairro Rancho Novo, a discrepância entre as duas classes de altura extremas era maior, com $37,3 \%$ dos indivíduos na classe de altura de 1,0 a $3,5 \mathrm{~m}$ e apenas $3,3 \%$ dos indivíduos com altura superior a $11 \mathrm{~m}$.

Entre as 20 espécies de maior ocorrência no Bairro Rancho Novo (Tabela 1), 60\% dos indivíduos de cássia siamea, $36 \%$ de sombreiro e $28 \%$ de amendoeira apresentaram altura superior a 8,5 m. Ficus benjamina, que foi a espécie com maior número de indivíduos, apresentou apenas quatro plantas $(3,5 \%)$ com altura superior a $8,5 \mathrm{~m}$. O restante dos indivíduos dessa espécie apresentam um grande potencial de conflitos futuros com redes de serviço e construções. As mangueiras com $66,6 \%$ de ocorrência apresentaram altura acima de $8,5 \mathrm{~m}$. O oiti, que foi a terceira espécie de maior ocorrência, não apresentou nenhum indivíduo com altura superior a esta.

No Bairro Centro, as espécies com maior freqüência relativa de indivíduos com altura superior a $8,5 \mathrm{~m}$ foram amendoeira (46\%), seguida de sombreiro (42\%), flamboyant (35\%) e oiti (32\%). Consultando a Tabela 2 , constatou-se que essas espécies são, respectivamente, a segunda, sétima, quarta e quinta em ordem de freqüência relativa. Cássia siamea, espécie de maior ocorrência nesse bairro, apresentou apenas 9\% dos indivíduos com altura superior a $8,5 \mathrm{~m}$, indicando que a espécie pode estar sofrendo intervenções freqüentes com poda. As seis espécies citadas anteriormente são consideradas de grande porte pela CEMIG (1995).

\subsection{Classes de diâmetro de copa}

Na Figura 2 são mostrados o número de indivíduos e a respectiva freqüência relativa das seis classes de copa. Constatou-se que apenas $0,5 \%$ dos indivíduos do Bairro Rancho Novo apresentava diâmetro médio de copa maior que $10 \mathrm{~m}$, ao passo que no Centro esse valor estava em torno de 7,5\%. Em ambos os bairros, a maior parte dos indivíduos apre- sentou diâmetro de copa na primeira classe de diâmetro (0 a 2,5 m). Isso, provavelmente, ocorreu devido à poda efetuada sempre que os indivíduos apresentavam conflito com a rede elétrica, postes de iluminação, ponto de ônibus e construções, conforme informações da Secretária Municipal de Urbanismo e Meio Ambiente de Nova Iguaçu.

As copas das árvores apresentavam características genéticas particulares, variando entre espécies. No entanto, em áreas urbanas as espécies podem sofrer alterações em sua conformação natural devido às condições peculiares ao desenvolvimento das espécies. Além disso, devido ao uso de espécies de porte inadequado, os órgãos públicos responsáveis pela arborização urbana sempre podam as árvores, alterando sua arquitetura e o tamanho da copa.

\subsection{Plantas sob a rede aérea}

No Bairro Rancho Novo, dos 560 indivíduos encontrados, $35 \%$ destes encontravam-se sob rede aérea. De acordo com a Tabela 3, observou-se que nesse bairro 126 indivíduos $(64,3 \%)$ não possuíam altura inferior a $6,0 \mathrm{~m}$, não apresentando, até o momento do levantamento, conflitos com rede aérea. Nessa classe de altura, as principais espécies, que totalizavam $57 \%$ do total de indivíduos, eram: fícus benjamina,

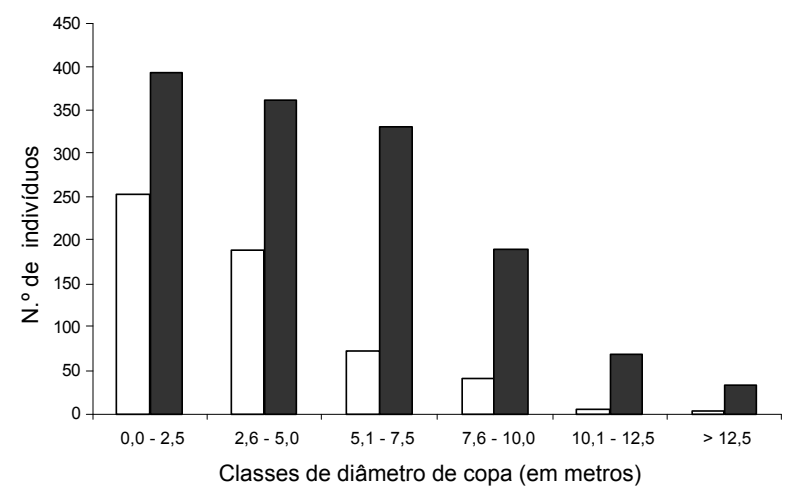

Figura 2 - Número de indivíduos, em diferentes classes de diâmetro de copa, da arborização de ruas dos Bairros Rancho Novo $(\square)$ e Centro ( $\square$ ), na cidade de Nova Iguaçu - RJ.

Figure 2-Number of individuals in different treetop diameter classes, of urban trees in Rancho Novo ( $\square$ ) and Downtown ( $\square$ ) districts, Nova Iguaçu, Rio de Janeiro State. 
extremosa, oiti, ipê-amarelo e amendoeira, respectivamente com 31, 20, 9, 7 e 5 indivíduos. Dessas espécies, apenas extremosa é adequada para plantio sob rede aérea, pois todas as outras são consideradas como de médio ou grande porte (CEMIG, 1995), podendo causar problemas com a fiação telefônica ou elétrica em um futuro muito próximo. Cerca de $34 \%$ dos indivíduos com altura inferior a 6,0 $\mathrm{m}$ apresentaram DAP superior a $10 \mathrm{~cm}$, indicando plantas na fase adulta que sofreram intervenções de poda, caracterizando a redução do seu porte. Das árvores sob rede aérea, 20,4\% estavam presentes na classe de altura superior e igual a 6,0 m e menor do que 7,2 $\mathrm{m}$ (Tabela 3 ). As espécies de maior ocorrência nessa situação foram: amendoeira, sombreiro, cássia siamea e ficus benjamina, respectivamente, com 10, 5, 4 e 4 indivíduos. Árvores com altura $\geq 7,2 \mathrm{~m}$ e já em conflitos com a rede elétrica correspondiam a aproximadamente $15 \%$ do total daquelas que estavam sob rede elétrica (Tabela 3). Entre as principais espécies estavam amendoeira e cassia siamea.

No Bairro Centro, onde foram encontrados 1.374 indivíduos arbustivos e arbóreos, aproximadamente $44 \%$ deles encontravam-se sob a rede aérea. Entre as espécies mais freqüentes nessas condições, com altura inferior a $6 \mathrm{~m}$, encontravam 319 indivíduos $(51,1 \%)$, em que se destacavam as espécies: ficus benjamina, representando $19,1 \%$ dos indivíduos, cássia siamea com $8,4 \%$, aroeira e extremosa com $7,1 \%$ e oiti com $5,5 \%$ (Tabela 3 ). Apenas aroeira e extremosa são adequadas para este tipo de plantio, por serem classificadas como de pequeno porte, conforme descrito pela CEMIG (1995). Entre os indivíduos com altura menor que $6,0 \mathrm{~m}, 42,4 \%$ possuíam DAP superior a $10 \mathrm{~cm}$, apresentando as mesmas condições dos do Bairro Rancho Novo. A classe de 6,0 a 7,2 m de altura foi representada com $22 \%$ dos indivíduos, aqueles que estavam sob rede aérea. As espécies mais freqüentes desta classe foram: cássia siamea, oiti, flamboyant, amendoeira e sombreiro, respectivamente com 31, 19, 14,8 e $7 \%$ de ocorrência. Na classe de 7,2 a $8,8 \mathrm{~m}$, $8,6 \%$ das árvores estavam sob rede aérea (Tabela 3 ), destacando-se as espécies: cássia siamea $(28,8 \%)$, flamboyant (17,3\%), oiti (15,4\%) e sombreiro $(7,7 \%)$. Já as espécies de maior ocorrência com altura superior a $8,8 \mathrm{~m}$, que representavam $18 \%$ da população sob rede aérea, foram cássia siamea $(42,7 \%)$, amendoeira e flamboyant $(15,5 \%)$ e sombreiro $(7,3 \%)$.
Tabela 3 - Número de indivíduos sob rede aérea, divididos em classes de altura nos Bairros Rancho Novo e Centro, na cidade de Nova Iguaçu - RJ. Os números entre parênteses indicam a porcentagem relativa de cada classe de altura do bairro

Table 3 - Number of individuals located under electrical lines, divided in height classes in Rancho Novo and Downtown districts of Nova Iguaçu, Rio de Janeiro State. The numbers between parentheses evidence the relative percentage of each class of height in the district

\begin{tabular}{lcr}
\hline Classes de altura & \multicolumn{2}{c}{ Bairro } \\
& Rancho Novo & \multicolumn{1}{c}{ Centro } \\
\hline$<6,0 \mathrm{~m}$ & $126(64,3 \%)$ & $309(51,1 \%)$ \\
$\geq 6,0-7,2 \mathrm{~m}$ & $40(20,4 \%)$ & $134(22,1 \%)$ \\
$\geq 7,2-8,8 \mathrm{~m}$ & $9(4,6 \%)$ & $52(8,6 \%)$ \\
$\geq 8,8 \mathrm{~m}$ & $21(10,1 \%)$ & $110(18,2 \%)$ \\
\hline
\end{tabular}

\subsection{Análise da freqüência dos tipos de poda}

As recomendações de poda no Bairro Centro demonstraram que $37,1 \%$ dos indivíduos não necessitavam de intervenção e $26,7 \%$, de poda de limpeza, com maior freqüência as espécies cássia siamea $(25,8 \%)$, flamboyant (15,3\%), amendoeira (13,3\%) e oiti (12,2\%). A poda de rebaixamento, consorciada com poda de limpeza, é recomendada para 18,4\% dos indivíduos, em maior freqüência nas espécies cássia siamea $(27,3 \%)$, oiti (18,2\%), flamboyant (11,9\%) e amendoeira (10,7\%). A poda de formação deve ser aplicada em 7,2\% dos indivíduos, com maior freqüência em ficus benjamina $(19,2 \%)$. A poda de conformação é recomendada para $4,7 \%$ dos indivíduos, destacando-se as espécies cássia siamea com $31,7 \%$ e amendoeira com $17,5 \%$ das ocorrências. A poda de conformação associada à poda de limpeza e a poda de remoção juntas são indicadas para 5\% dos indivíduos do bairro.

No Bairro Rancho Novo, a poda de limpeza é recomendada a 50,4\% dos indivíduos, estando em maior ocorrência as espécies ficus benjamina com 14,5\%, amendoeira com $12,4 \%$ e cássia siamea com $8,9 \%$. A poda de formação é recomendada a $7 \%$ dos indivíduos, com 33,3\% de ocorrência para ficus benjamina e $23,1 \%$ para ipê-amarelo, enquanto a poda de rebaixamento consorciada com poda de limpeza representa 3,6\%. Em aproximadamente $35 \%$ dos indivíduos não se observou necessidade de podas.

R. Árvore, Viçosa-MG, v.28, n.4, p.599-607, 2004 


\subsection{Distribuição dos indivíduos}

$\mathrm{Na}$ avaliação da distribuição das plantas nas vias públicas, observaram-se diferenças entre os bairros. Na Tabela 4, mostram-se a distribuição total e o número de árvores a cada $10 \mathrm{~m}$ de calçada.

No Bairro Rancho Novo foram encontrados 560 indivíduos, distribuídos em 45 vias públicas. $\mathrm{O}$ bairro possuía 59 vias públicas, 17 destas apresentando apenas um indivíduo, contra 14 com nenhum. No Centro, esses números correspondiam, respectivamente, a 1.374, 153,12 e 30.

Nos Bairros Rancho Novo e Centro, o número de plantas a cada $10 \mathrm{~m}$ linear de via pública apresentava valores de 0,358 e 0,269, respectivamente. Esses valores eram inferiores aos encontrados por Crispim (2000) nos Bairros de Paulo de Frontin $(0,509)$ e Vila Santa Cecília $(0,555)$, na avaliação da arborização em Volta Redonda, RJ. Milano e Dalcin (2000) consideraram para uma arborização urbana adequada que, em média, a cada $10 \mathrm{~m}$ de calçada deva existir um indivíduo arbustivo ou arbóreo.

No Bairro Rancho Novo não existia nenhum indivíduo arbustivo ou arbóreo em 23,7\% das vias públicas. Em contrapartida, no Centro esse valor foi de 19,6\%. A distância média entre árvores foi de 56 $\mathrm{m}$ em Rancho Novo e de $74 \mathrm{~m}$ no Centro. Tais valores estão acima dos encontrados por Milano (1984) na avaliação da arborização urbana de Curitiba e por Biondi (1985) na de Recife. O Bairro Rancho Novo apresentava $18 \%$ das vias públicas arborizadas, e no Bairro Centro esse valor era de apenas $13,5 \%$, evidenciando a má qualidade da arborização de ambos os bairros.

Tabela 4 - Distribuição dos indivíduos arbustivos e arbóreos encontrados nos Bairros Rancho Novo e Centro, na cidade de Nova Iguaçu, RJ

Table 4 -Distribution of shrub/tree individuals found in Rancho Novo and Downtown districts, Nova Iguaçu, Rio de Janeiro State

\begin{tabular}{lccc}
\hline & Rancho Novo & Centro & Total \\
\hline $\begin{array}{l}\text { Número total } \\
\text { de vias públicas }\end{array}$ & 59 & 153 & 212 \\
$\begin{array}{l}\text { Extensão total } \\
\text { das vias públicas (m) }\end{array}$ & 15.640 & 50.980 & 66.620 \\
$\begin{array}{l}\text { Extensão de } \\
\text { calçada* (m) }\end{array}$ & 31.280 & 101.960 & 133.240 \\
$\begin{array}{l}\text { Número total de plantas } \\
\text { Número de plantas }\end{array}$ & 560 & 1374 & 1934 \\
$/ 10$ m de calçada & 0,179 & 0,135 & 0,145 \\
\hline
\end{tabular}

* considera que toda via pública possui calçada dos dois lados.

\section{CONCLUSÕES}

O Bairro Rancho Novo, provavelmente por ser residencial, apresentou melhor qualidade de sua arborização em relação ao Bairro Centro. Cerca de $60 \%$ dos indivíduos desses bairros necessitavam de poda, destacando-se as espécies cássia siamea no Bairro Centro e ficus benjamina no Bairro Rancho Novo.

As espécies ficus benjamina, cássia siamea, amendoeira, flamboyant e sombreiro apresentaram-se inadequadas para a arborização de vias públicas devido à incompatibilização com estruturas urbanas.

O equilíbrio entre diversidade de espécies e identidade dos bairros, nas condições analisadas, foi considerado inadequado, tornando necessária a substituição gradativa das espécies mais problemáticas encontradas neste estudo por espécies mais adequadas às condições urbanas.

\section{REFERÊNCIAS BIBLIOGRÁFICAS}

BIONDI, D. Diagnóstico da arborização de ruas da Cidade de Recife . 1985. $167 \mathrm{f}$. Dissertação (Mestrado em Engenharia Florestal) Universidade Federal do Paraná, Curitiba, 1985.

CEMIG. Manual de arborização. Belo Horizonte: Diretoria de Desenvolvimento do IEF, [1995], 23p.

CEMIG. Programa de compatibilização da arborização com a rede de distribuição de energia aérea. Belo Horizonte: Superintendência de Coordenação de Ações e Estudos sobre Meio Ambiente, 1994. 30 p.

COSTA, L. A.; HIGUCHI, N. Arborização de ruas de Manaus: avaliação qualitativa e quantitativa. Revista Árvore, v. 23, n. 2, p. 223-232, 1999.

COSTA, L. M. S. A.; et al. Arborização das ruas do Bairro de Copacabana. In: CONGRESSO BRASILEIRO DE ARBORIZAÇÃO URBANA, 3., 1996, Salvador. Anais... Salvador: Sociedade Brasileira de Arborização Urbana, 1996. p.79-88.

COUTINHO, C.L. et al. Oncideres saga (Dalman, 1823) (coleóptera, cerambycidae) e a arborização urbana em Seropédica, RJ. Floresta e

Ambiente, v.51, p.50-54, 1998. 
CRISPIM, A. A. Arborização urbana em Volta Redonda - RJ: levantamento nos Bairros Paulo de Frontin e Vila Santa Cecília. 2000. 180f. Dissertação (Mestrado em Ciências Ambientais e Florestais). Universidade Federal Rural do Rio de Janeiro, Seropédica, 2000.

GUAJARÁ, M.S. Aspectos bionômicos de Euphalerus clitorae Buckhardt \& Guajará (Hemiptera: Phylloidae). 2001. 102f. Dissertação (Doutorado em Fitotecnia). Universidade Federal Rural do Rio de Janeiro, Seropédica, 2000.

IBGE. Censo 2000. Disponível em: <http:// www.ibge.gov.br>. Acesso em: 12 abr. 2002.

MILANO, M. S. Avaliação qualiquantitativa e manejo da arborização urbana: exemplo de Maringá - PR . 1988. 120f. Tese (Doutorado em. Engenharia Florestal). Universidade Federal do Paraná, Curitiba, 1988.

Milano, M. S. Avaliação e análise da arborização de ruas de Curitiba . 1984. 130 f. Dissertação (Mestrado em Engenharia Florestal). Universidade Federal do Paraná, Curitiba, 1984.

MILANO, M. S. Métodos de amostragem para avaliação de arborização de ruas. In: CONGRESSO BRASILEIRO DE ARBORIZAÇÃO URBANA, 2., 1994, São Luís. Anais... São Luís: Sociedade Brasileira de Arborização Urbana, 1994. p. 163-168.

MILANO, M.; DALCIN, E. Arborização de vias públicas. Rio de Janeiro: LIGHT, 2000. $226 \mathrm{p}$.

MONTEIRO, R.F.; CAMPOS, A.T.S. Desfolhamento de sombreiro - Clitoria fairchildiana (Leguminosae) por Urbanus acawoios (Lepidóptera: Hesperidae): um exemplo para arborização urbana. In: SICONBIOL SIMPÓSIO DE CONTROLE BIOLÓGICO, 4.; 1994, Gramado. Anais... Gramado: EMPBRAPA CPACT, 1994. p.269.

MOTTA, G. L. O. Inventário da arborização de áreas, utilizando um sistema hierárquico para endereço impreciso. 1998. 120 f. Dissertação (Mestrado em Ciências Florestais) - Universidade Federal de Viçosa, Viçosa, 1998.
PROTETORES DA VIDA. O Município de Nova Iguaçu: clima, vegetação e fauna. Disponível em: <http:// www.protetoresdavida.org.br/novaiguacu/ clima.htm>. Acesso em: 25 abr. 2002a.

PROTETORES DA VIDA. O Município de Nova Iguaçu: dados gerais. Disponível em: $<$ http://www.protetoresdavida.org.br/novaiguacu/ dados.htm>. Acesso em: 25 abr. 2002 b.

ROBAYO, J. A. M. Inventário da arborização de ruas. In: CURSO de arborização urbana. Curitiba: Universidade Livre do Meio Ambiente, 1993. p. 82-92.

SANCHOTENE, M. C. C. Desenvolvimento e perspectivas da arborização urbana no Brasil. In: CONGRESSO BRASILEIRO DE ARBORIZAÇÃO URBANA, 2., 1994, São Luís. Anais... São Luís: Sociedade Brasileira de Arborização Urbana, 1994. p.15-26.

SANTANA, J.R. F.; SANTOS, G.M.M. Arborização do campus da UEFS: exemplo a ser seguido ou um grande equívoco? Sitientibus, n.20, p.103-107, 1999.

SILVA, A.G. Importância da vegetação em ambientes urbanos. Viçosa, MG: UFV, 1998, 36p. (Monografia de Graduação).

SILVA, A. G. Arborização urbana em cidades de pequeno porte: avaliação quantitativa e qualitativa . 2000. $150 \mathrm{f}$. Dissertação (Mestrado em Ciências Florestais), Universidade Federal de Viçosa, Viçosa, 2000.

TAKAHASHI, L. Y. Arborização urbana: inventário. In: CONGRESSO BRASILEIRO DE ARBORIZAÇÃO URBANA, 2., 1994, São Luís. Anais... São Luís: Sociedade Brasileira de Arborização Urbana, 1994. p.193-200.

TEIXEIRA, I. F.; SANTOS, N. R. Z. S.; HURTADO, R. R. Avaliação da vegetação das ruas e áreas verdes dos loteamentos da Cidade de Santa Maria - RS. In: CONGRESSO BRASILEIRO DE ARBORIZAÇÃO URBANA, 2., 1994, São Luís. Anais... São Luís: Sociedade Brasileira de Arborização Urbana, 1994. p.389-401.

VIDAL, M.; GONÇALVES, W. Curso de paisagismo. Viçosa, MG: UFV, 1999. 76 p.

R. Árvore, Viçosa-MG, v.28, n.4, p.599-607, 2004 